\title{
The Effects of Insufflation Conditions on Rat Mesothelium
}

\author{
Andrew K. Davey, ${ }^{1,2}$ Jessica Hayward, ${ }^{3}$ Jean K. Marshall, ${ }^{3,4}$ and Anthony E. Woods ${ }^{2}$ \\ ${ }^{1}$ Research Centre for the Molecular Basis of Disease, Griffith Health Institute, Griffith University, Gold Coast, QLD 4222, Australia \\ ${ }^{2}$ School of Pharmacy and Medical Science, University of South Australia, Adelaide, SA 5001, Australia \\ ${ }^{3}$ Fisher \& Paykel Healthcare Limited, 15 Maurice Paykel Road, East Tamaki, Auckland 2013, New Zealand \\ ${ }^{4}$ Graduate School of Medicine and Illawarra Health and Medical Research Institute, University of Wollongong, Wollongong, \\ NSW 2500, Australia
}

Correspondence should be addressed to Andrew K. Davey; a.davey@griffith.edu.au

Received 27 March 2013; Revised 11 June 2013; Accepted 11 June 2013

Academic Editor: G. Rogler

Copyright (c) 2013 Andrew K. Davey et al. This is an open access article distributed under the Creative Commons Attribution License, which permits unrestricted use, distribution, and reproduction in any medium, provided the original work is properly cited.

\begin{abstract}
Aim. The aim of this investigation was to examine the alterations in the peritoneum after cold dry $\mathrm{CO}_{2}$, heated dry $\mathrm{CO}_{2}$, and humidified heated $\mathrm{CO}_{2}$ at pressures equivalent to intraperitoneal pressures used in human laparoscopy. Methods. Eighteen rats were divided into 4 treatment groups-group 1: untreated control; group 2: insufflation with cold dry $\mathrm{CO}_{2}$; group 3: insufflation with heated, dry $\mathrm{CO}_{2}$; group 4: insufflation with heated and humidified $\mathrm{CO}_{2}$. The abdomen was insufflated to $5 \mathrm{~mm} / \mathrm{Hg}$ (flow rate $50 \mathrm{~mL} / \mathrm{min}$ ) for $2 \mathrm{~h}$. Twelve hours later, tissue samples were collected for analysis by light microscopy (LM) and scanning electron microscopy (SEM). Results. Group 1: no abnormalities were detected. Group 2: specimens revealed an inflammatory response with loss of mesothelium and mesothelial cell nuclei showing lytic change. Cells were rounded with some areas of cell flattening and separation. Group 3: some animals showed little or no alteration, while others had a mild inflammatory response. Mesothelial cells were rounded and showed crenation on the exposed surface. Group 4: specimens showed little change from the control group. Conclusions. The LM results indicate that insufflations with heated, humidified $\mathrm{CO}_{2}$ are the least likely to induce mesothelial damage.
\end{abstract}

\section{Introduction}

Carbon dioxide $\left(\mathrm{CO}_{2}\right)$ gas is the most common insufflation agent used to create pneumoperitoneum during laparoscopic surgery [1]. In the absence of conditioning, standard $\mathrm{CO}_{2}$ used in laparoscopic surgery is cold and dry at 20 to $21^{\circ} \mathrm{C},<1 \%$ relative humidity, at the point of entry into the peritoneal cavity $[2,3]$. The condition of standard $\mathrm{CO}_{2}$ is in marked contrast to the physiologic intra-abdominal condition. Experimental and clinical investigations have demonstrated that the cool, dry nature of standard $\mathrm{CO}_{2}$ insufflation causes desiccation resulting in visible structural, morphological, and biochemical alterations to the mesothelial cells of the peritoneum [48]. This includes bulging of the mesothelial cells, widening of intercellular junctions, exposure of the basement membrane [5], and increased peritoneal cytokine response [9]. Previous animal investigations have demonstrated that the use of humidified heated $\mathrm{CO}_{2}$ can attenuate peritoneal damage caused by desiccation $[4,6]$. Compared to standard $\mathrm{CO}_{2}$ insufflation, the use of humidified heated $\mathrm{CO}_{2}$ results in no exposure of the basement membrane [4], no visible intercellular clefts [4], improvements in perioperative temperature, and decreased adhesion formation [6]. However, insufflation during these animal investigations was performed in rodent models at pressures greater than $8 \mathrm{mmHg}$. The more recent literature indicates that pneumoperitoneal pressures $\geq 8 \mathrm{mmHg}$ in a rat model correlate to high intraperitoneal pressures in humans, greater than the standard working pressures [10]. An excessively high intraperitoneal pressure may cause detachment of mesothelial cells by a mechanical effect, severe hypoxia, or both [11]. In addition, these studies fail to assess the effect of heated-only $\mathrm{CO}_{2}$ on the peritoneum. The aim of this investigation was to examine the alterations of the peritoneum after standard cold dry $\mathrm{CO}_{2}$, heated dry $\mathrm{CO}_{2}$, and humidified heated $\mathrm{CO}_{2}$ at pressures equivalent to intraperitoneal pressures used in human laparoscopy. 


\section{Materials and Methods}

2.1. Animal Protocol. This study was approved by the Institute of Medical and Veterinary Science (IMVS) Animal Ethics Committee (Adelaide, SA, Australia). Male Sprague-Dawley rats were obtained from the Animal Resource Centre (Gilles Plains, SA, Australia) and kept in individual cages on a $12 \mathrm{~h}$ light-dark cycle, with free access to standard diet and water in a room at a temperature of 20 to $23^{\circ} \mathrm{C}$. They were divided into treatment groups:

group 1-control: no insufflation, anaesthesia only $(n=3)$;

group 2: insufflation with cold (room temperature), dry $\mathrm{CO}_{2}$ at a pressure of $5 \mathrm{mmHg}(n=5)$;

group 3: insufflation with heated $\left(37^{\circ} \mathrm{C}\right), \operatorname{dry~} \mathrm{CO}_{2}$ at a pressure of $5 \mathrm{mmHg}(n=5)$;

group 4: insufflation with heated $\left(37^{\circ} \mathrm{C}\right)$ and humidified $(100 \% \mathrm{RH}) \mathrm{CO}_{2}$ at a pressure of $5 \mathrm{mmHg}(n=5)$.

$\mathrm{CO}_{2}$ in groups 3 and 4 was conditioned using the Fisher \& Paykel Healthcare MR860 Laparoscopic Humidification System (LHS) (Fisher \& Paykel Healthcare, Auckland, New Zealand). Under standard use, as per study group 4, the insufflation gas passes over a heated humidification chamber filled with $30 \mathrm{~mL}$ of sterile water which is designed to condition the gas to $37^{\circ} \mathrm{C}$ and $100 \% \mathrm{RH}$ [12]. The condition of the gas is maintained as it flows down the humidified insufflation tube which acts to maintain the condition of the gas direct to the laparoscopic port. The system monitors the temperature and flow rate of the gas and automatically alters the heater-plate temperature to maintain consistent gas conditions. For group 3, the system was used off-label as no water was added to the humidification chamber resulting in warm $\left(37^{\circ} \mathrm{C}\right)$, dry insufflation gas.

On the day of the experiment, the rats were anaesthetised with inhaled isoflurane. Prior to use, gas was passed through the LHS until reaching $37^{\circ} \mathrm{C}$. The gas flow rate was continually measured using a thermal mass flow meter ("redy smart series”, Vogtlin Instruments AG, Aesch, Germany) calibrated for use with $\mathrm{CO}_{2}$ gas. The flow rate was adjusted to $50 \mathrm{~mL} / \mathrm{min}$ via a flow restrictor (Precision Flow Control Valve, GRPO-10-PK-3, Esslingen, Germany). The target flow rate of $50 \mathrm{~mL} / \mathrm{min}$ was calculated according to the average peritoneal surface area of the experimental rats [13]. The abdomen was insufflated $\left(\mathrm{CO}_{2}\right.$-OP-Pneu Insufflator, Wisap, Munich, Germany) to $5 \mathrm{~mm} / \mathrm{Hg}$ through a $16 \mathrm{G}$ port site cannula inserted into the side of the lower abdomen. When there was no gas flow, a $26 \mathrm{G}$ exit port cannula was inserted into the opposite side of the abdomen. Rats were kept under anaesthesia for 2 hours. Body temperature was measured with a rectal thermometer during insufflation and normothermia maintained using a warming pad beneath the animal. The temperature was recorded every $15 \mathrm{~min}$, and no significant changes in body temperature were observed. At the end of the $2 \mathrm{~h}$ experimental period, the $\mathrm{CO}_{2}$ was turned off and disconnected. The rats were allowed to rest for 1 to $2 \mathrm{~min}$ to allow gas to escape through the cannulae. Once the abdomen had finished deflating, the cannulae were gently removed and the abdominal wall closed with surgical silk. Following surgery, the anaesthetic was switched off, and the rats were allowed to recover.

2.2. Tissue Collection and Analysis. Twelve hours after the completion of surgery, the rats were again anaesthetised with isoflurane. After opening the abdomen, tissue samples were collected at several sites along the abdominal wall. Only samples collected away from the insertion sites were used in order to avoid physical trauma from the incision or the cannula confounding the results. Rats were euthanised immediately after tissue sample collection. Specimens were collected from each study group and fixed by immersion for at least $24 \mathrm{~h}$ in $10 \%$ buffered formalin for examination by light microscopy (LM) or 2.5\% glutaraldehyde for scanning electron microscopy (SEM).

2.3. Light Microscopy. Fixed samples were processed in an automated processor (LEICA ASP300S, Leica Microsystems, Wetzlar, Germany) into paraffin wax using a routine schedule (70\% ethanol, 90\% ethanol, absolute ethanol, xylene, and paraffin wax).

Paraffin sections were cut at $4 \mu \mathrm{m}$ thickness using a Microm (HM 325, Walldorf, Germany) microtome and collected onto slides. Sections were stained using a standard H\&E procedure, coded, and examined blind to the code used. Inflammatory cells (neutrophils, eosinophils, and macrophages) were identified morphologically. The inflammatory cell concentration along the mesothelium and submesothelial lamina propria was determined according to the following semiquantitative scale:,$+ 0-5$ cells per high power ( $\times 40$ objective) field (hpf); ++, 6-15 cells per hpf; +++, >15 cells per hpf. Micrographs were captured using an Olympus BX40 microscope (Olympus, Hamburg, Germany) fitted with a DP70 digital camera linked to Olympus Cell ${ }^{\wedge} \mathrm{B}$ Imaging Software (Olympus Soft Imaging Solution $\mathrm{GmbH}$, Munster, Germany).

2.4. Scanning Electron Microscopy. Fixed samples were washed in $0.1 \mathrm{~mol} / \mathrm{L}$ cacodylate buffer then postfixed in $1 \%$ osmium tetroxide for $90 \mathrm{~min}$. Following a further wash in the buffer, samples were dehydrated through a graded alcohol series to super dry alcohol then completely dried in a critical-point drying apparatus using liquid $\mathrm{CO}_{2}$ as the exchange medium. Dehydrated specimens were mounted onto aluminium stubs then coated with carbon/gold in a Denton DV-502 Vacuum Coater (Denton Vacuum, LLC, New Jersey, USA). Tissue specimens were examined using a Philips XL20 SEM (Philips, Eindhoven, The Netherlands) operated at $10 \mathrm{kV}$. The spot size was recorded directly on the images.

\section{Results}

3.1. Light Microscopy. Light microscopy observations are detailed in Table 1. A number of sections showed some level of physical damage, drying and/or stretching artefact due to the sample collection process (data not shown). Within group 1 
TABLE 1: Summary of light microscopy (LM) observations $12 \mathrm{~h}$ after insufflation with $\mathrm{CO}_{2}$ for $2 \mathrm{~h}$ at $5 \mathrm{~mm} / \mathrm{Hg}$.

\begin{tabular}{|c|c|}
\hline \multicolumn{2}{|c|}{ Group 1} \\
\hline A & NAD \\
\hline B & NAD \\
\hline $\mathrm{C}$ & NAD \\
\hline \multicolumn{2}{|c|}{ Group 2} \\
\hline A & NAD \\
\hline B & $\begin{array}{l}\text { Inflammatory cell infiltrate }(++) \\
\text { Fragmentation and desquamation of mesothelium in } \\
\text { some sections }\end{array}$ \\
\hline $\mathrm{C}$ & $\begin{array}{l}\text { Inflammatory cell infiltrate }(+++) \\
\text { Some inflammatory cells migrated onto mesothelium } \\
\text { surface }\end{array}$ \\
\hline $\mathrm{D}$ & Inflammatory cell infiltrate $(+)$ \\
\hline $\mathrm{E}$ & $\begin{array}{l}\text { Inflammatory cell infiltrate variable in concentration } \\
\text { along mesothelium (+ to }+++) \\
\text { Inflammatory cells migrated onto mesothelium surface }\end{array}$ \\
\hline \multicolumn{2}{|c|}{ Group 3} \\
\hline A & $\begin{array}{l}\text { Inflammatory cell infiltrate }(+++) \text { with cells on } \\
\text { mesothelial surface } \\
\text { Loss of mesothelium in some sections of intense } \\
\text { inflammatory cell infiltration } \\
\text { Remaining areas uninvolved }\end{array}$ \\
\hline B & Scant areas of inflammatory cell infiltrate $(+)$ \\
\hline $\mathrm{C}$ & $\begin{array}{l}\text { Inflammatory cell infiltrate }(++) \\
\text { Mesothelial cell nuclei rounded and projecting above } \\
\text { mesothelial surface }\end{array}$ \\
\hline $\mathrm{D}$ & Scant areas of inflammatory cell infiltrate $(+)$ \\
\hline $\mathrm{E}$ & Scant areas of inflammatory cell infiltrate $(+)$ \\
\hline \multicolumn{2}{|c|}{ Group 4} \\
\hline A & Patches of inflammatory cell infiltrate $(+)$ \\
\hline B & Inflammatory cell infiltrate $(+$ to ++$)$ \\
\hline $\mathrm{C}$ & Patches of inflammatory cell infiltrate $(+$ to +++$)$ \\
\hline $\mathrm{D}$ & Patches of inflammatory cell infiltrate $(+)$ \\
\hline $\mathrm{E}$ & NAD \\
\hline
\end{tabular}

Group 1: control animals, no treatment with $\mathrm{CO}_{2}$. Group 2: insufflation with room temperature, dry $\mathrm{CO}_{2}$. Group 3: insufflation with warm, dry $\mathrm{CO}_{2}$. Group 4: insufflation with warm, humidified $\mathrm{CO}_{2}$. Letters (A-E) refer to individual rats. NAD: no abnormality detected.

(control) no tissue changes were detected in any specimen (Figure 1(a)).

Following insufflation with cold (room temperature), dry $\mathrm{CO}_{2}$ (group 2), most specimens revealed an inflammatory response indicated by a mixed population of acute inflammatory cells consisting of neutrophils, eosinophils, and macrophages (Figure 1(b)). The extent of the inflammatory infiltrate was variable ranging from very few cells to an intense inflammatory response which extended to both sides of the mesothelial surface (Figure 1(b) inset). Loss of the mesothelium was evident in some areas.

Variable results were noted in group 3 (heated and dry). Some animals showed little or no alteration to the mesothelium, while in others a mild nonspecific inflammatory response was observed. Rat C (Figure 1(c)) displayed isolated areas which exhibited a more prominent inflammatory infiltrate and rounded mesothelial cells. The changes observed might reflect the changes to the intra-abdominal environment but this cannot be confirmed without additional studies.

The morphology of the samples exposed to heated and humidified $\mathrm{CO}_{2}$ (group 4) was similar to that in the control group: the mesothelium was intact, and there was little inflammatory cell infiltrate (Figure $1(\mathrm{~d})$ ). The latter noted in rats $\mathrm{B}$ and $\mathrm{C}$ may reflect the changes to the intra-abdominal environment but this cannot be confirmed without additional studies.

3.2. Scanning Electron Microscopy. The changes identified by SEM mirrored the changes noted by LM although inflammatory cells were not seen in any of the specimens examined. As these cells are not usually firmly anchored in tissues, the likelihood is that any cells that were present were unintentionally removed from the surface during preparation.

The control samples showed cells aligned in rows with some elevation (Figure 2). Microvilli were scantly present which is a characteristic of the flat mesothelial cells of the parietal peritoneum [14].

Group 2 (room-temperature, dry $\mathrm{CO}_{2}$ ) cells were distinctly rounded with some areas of cell flattening and separation (Figure 3). Microvilli were collapsed and poorly defined. Some invagination of the tissue suggestive of dehydration was evident in occasional regions.

In group 3 (warm, dry $\mathrm{CO}_{2}$ ), mesothelial cells were rounded and showed distinct indentations (crenation) on the exposed surface (Figure 4). This was probably due to exposure to the dry environment. Within group 4 (humidified, heated $\mathrm{CO}_{2}$ ), the cells were closely apposed with cytoplasmic projections (microvilli) prominent (Figure 5). While some rounding of the cells was evident, overall this group showed similar morphology to the control samples indicating it exhibited the least effects from the induced environment.

\section{Discussion}

The use of insufflating gas facilitates laparoscopy by lifting the abdominal wall and creating a working space [1]. The ideal gas would be nontoxic, odourless, colourless, highly soluble, readily excreted by the lungs, and noncombustible/does not support combustion and inexpensive. Insufflation gases currently in use all have limitations. Helium and argon are inert but poorly soluble which leads to concerns relating to potential embolism and pneumothorax; nitrous oxide can explode when using electrocautery; and $\mathrm{CO}_{2}$ may cause local and systemic acidosis and cardiorespiratory effects (reviewed by Neuhaus et al., 2001 [1]). Of these gases, $\mathrm{CO}_{2}$ is by far the most commonly used, its major advantages over the alternatives being that it is very soluble and rapidly excreted.

Despite the advantages of using $\mathrm{CO}_{2}$ as an insufflation gas in laparoscopic surgery, it has been associated with pain, including during awake laparoscopy [15], postsurgery 


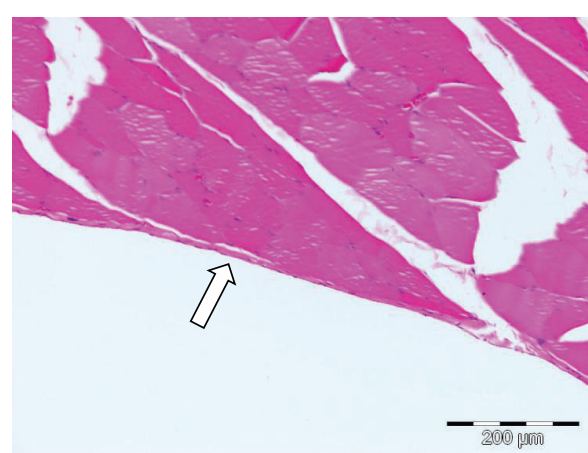

(a)

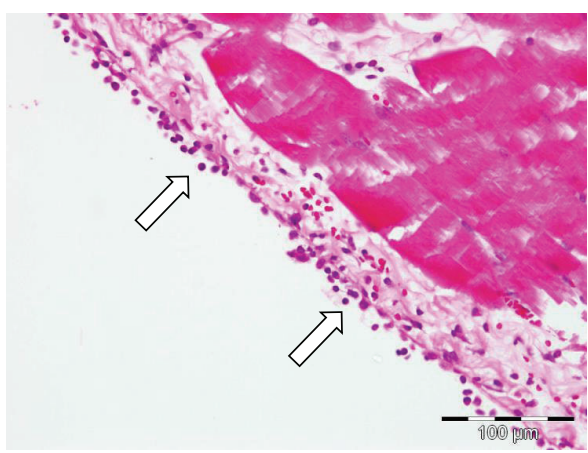

(c)

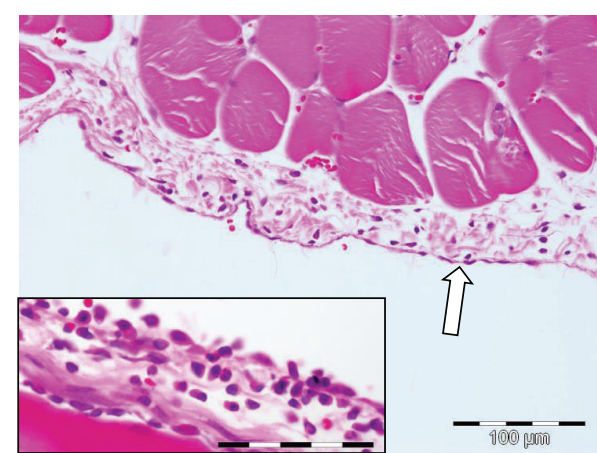

(b)

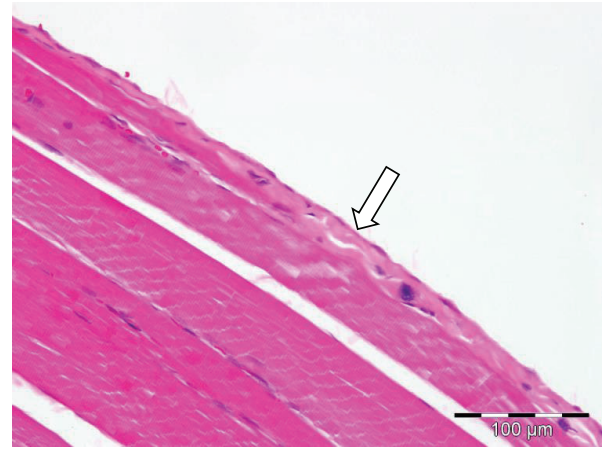

(d)

FIGURE 1: Selected light micrographs showing the mesothelial surface $12 \mathrm{~h}$ after insufflation with $\mathrm{CO}_{2}$ for $2 \mathrm{~h}$ at $5 \mathrm{~mm} / \mathrm{Hg}$ of (a) control animals, no treatment with $\mathrm{CO}_{2}$; (b) insufflation with room-temperature, dry $\mathrm{CO}_{2}$ where inflammatory cells are evident in the lamina propria. Inset: inflammatory cells on surface of mesothelium (scale bar $=100 \mu \mathrm{m}$ ); (c) insufflation with heated, dry $\mathrm{CO}_{2}$. Inflammatory cells are evident on the mesothelial surface; (d) insufflation with warm, humidified $\mathrm{CO}_{2}$ with normal mesothelium. Arrows indicate the mesothelial surface.

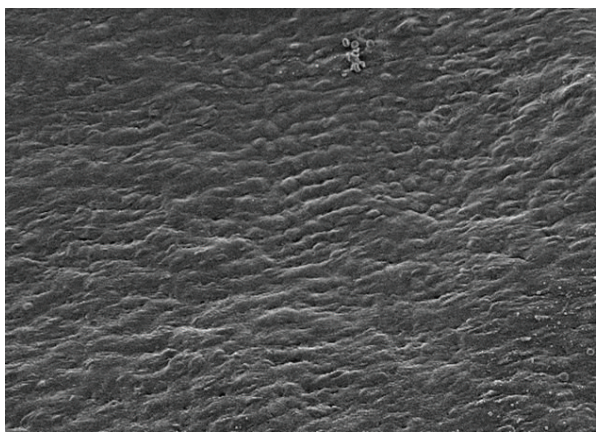

(a)

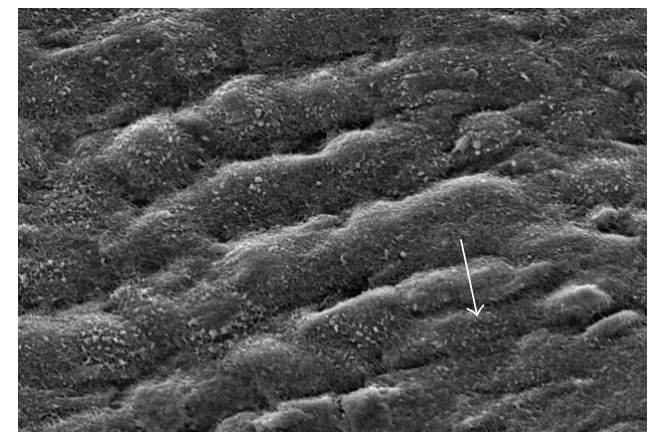

(b)

FIGURE 2: SEM showing mesothelial surface from control animals (group 1). Cells are aligned in rows with some elevation; microvilli are present but sparse $($ arrow): (a) original $\times 650$; (b) original $\times 3500$.

shoulder-tip pain [16], adhesion formation [6, 17], and increased susceptibility to cancer metastasis [18]. Most of these adverse effects are linked to damage and/or inflammatory activity to the peritoneal mesothelium, and there are several putative mechanisms by which pneumoperitoneum can cause mesothelial damage. $\mathrm{CO}_{2}$ dissolves in water to form carbonic acid which is suggested to lead to peritoneal acidosis [19]. Alternatively, if the gas is used at high pressure, it can increase airway pressure [10] and reduce cardiac output and peritoneal blood flow leading to acidosis, hypoxia, and oxidative stress $[11,20]$. This is a particular concern when extrapolating experimental results from small animal models, where disproportionally high insufflation pressures are often used $[10,11]$. The condition of the gas is also a factor. Generally, $\mathrm{CO}_{2}$ is administered at room temperature (cold) and at very low relative humidity (dry). Cold gas is associated with hypothermia which is linked to numerous postoperative problems [21], although some slight cooling in the absence of desiccation may be protective [17], presumably due to suppression of the immune system and reduction 


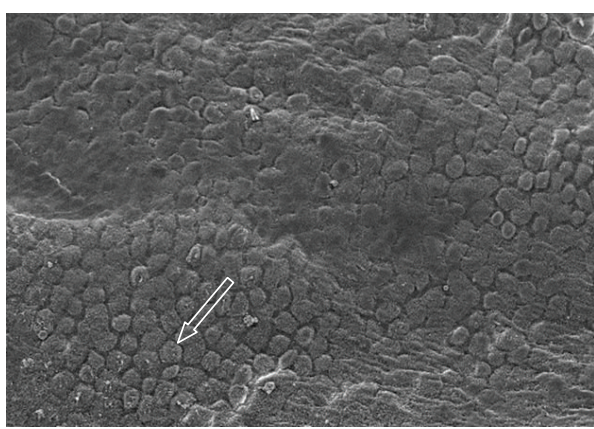

(a)

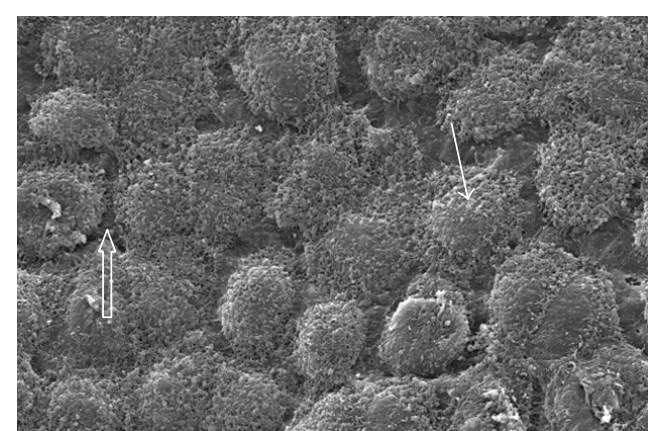

(b)

FIGURE 3: SEM showing mesothelial surface from rats $12 \mathrm{~h}$ after insufflation with room-temperature, dry $\mathrm{CO}_{2}$ for $2 \mathrm{~h}$ at $5 \mathrm{~mm} / \mathrm{Hg}$ (group 2). Cells are distinctly rounded with some areas of cell flattening and separation (open arrow). Microvilli are collapsed and indistinct (arrow). Some invagination of the tissue suggestive of dehydration is evident in some regions: (a) original $\times 650$; (b) original $\times 3500$.

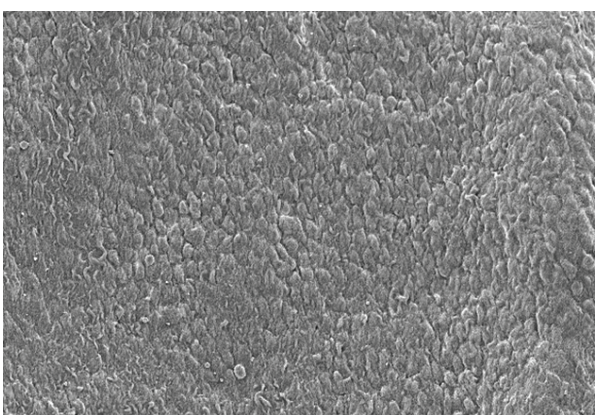

(a)

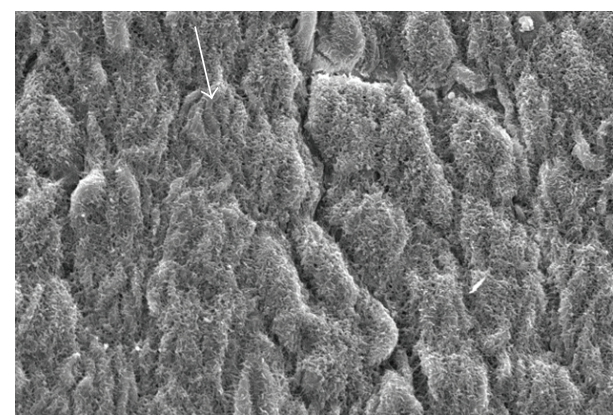

(b)

FIGURE 4: Mesothelial surface from rats $12 \mathrm{~h}$ after insufflation with warm, dry $\mathrm{CO}_{2}$ for $2 \mathrm{~h}$ at $5 \mathrm{~mm} / \mathrm{Hg}$ (group 3). Mesothelial cells are rounded and show distinct indentations (crenation) to the exposed surface (arrow): (a) original $\times 650$; (b) original $\times 3500$.

of the metabolic activity of the cells. Using dry gas can damage the mesothelium also due to water evaporating from the peritoneal surface causing desiccation of the cells and further contributing to the hypothermia through the evaporative cooling effect $[17,21,22]$. The insult to the mesothelium through a combination of these mechanisms induces an inflammatory response which further acts to damage the tissue including sloughing of cells [7], which increases susceptibility to cancer spread [23] and adhesion formation [24].

The extent of mesothelial damage would be expected to increase with longer duration of pneumoperitoneum as well as with higher pressures and flow rates [22, 25, 26]. Hence, any protective effect through conditioning of the gas should become more apparent under those conditions where damage is likely to be substantial (i.e., long duration, high pressure, and high flow rate). The use of heated gas may have some protective effects against hypothermia and inflammation [9]. However, the dominant mechanism by which gas insufflation causes heat loss is through evaporative cooling [27]. When the gas is heated without humidification, it has an even greater potential to cause evaporation than unheated gas that can lead to increased tissue cooling and to much greater tissue desiccation. This may explain why heated gas may be associated with increased postoperative pain [28]. Humidification of the
$\mathrm{CO}_{2}$ as well as heating can deliver gas to the peritoneum that should not cause desiccation. Care does need to be taken to ensure that the temperature/humidification combination is correct such that condensation of water does not occur in the peritoneum, which causes osmotic shifts [27]. Heating and humidification can reduce pain and improve postoperative recovery [29-31] by a number of potential mechanisms. Glew et al. demonstrated that residual gas dissipated more quickly after surgery in piglets when it was humidified [32]. This was attributed to the preservation of the moist milieu of the serous fluid lining of the peritoneal cavity, enabling the $\mathrm{CO}_{2}$ to rapidly dissolve. Within that study, humidification was also associated with a reduced systemic cytokine response. The ability of the $\mathrm{CO}_{2}$ to dissolve and dissipate rapidly may reduce the potential for localised acidosis too. Despite their ultimate conclusion, Wong et al. demonstrated a more acidic peritoneum when using standard cold dry gas compared to heated and humidified $(P<0.05)$ in pigs [19]. Reduction of evaporation by humidifying the gas significantly reduces the potential for hypothermia as well $[6,21]$. However, the greatest benefit of heated and humidified gas potentially rests in the prevention of mesothelial damage through desiccation and the associated inflammatory response. But there is a paucity of studies that investigate this in animal models, and of those the majority uses insufflation conditions 


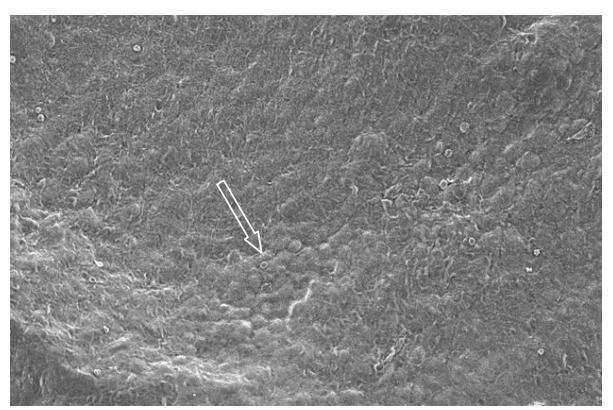

(a)

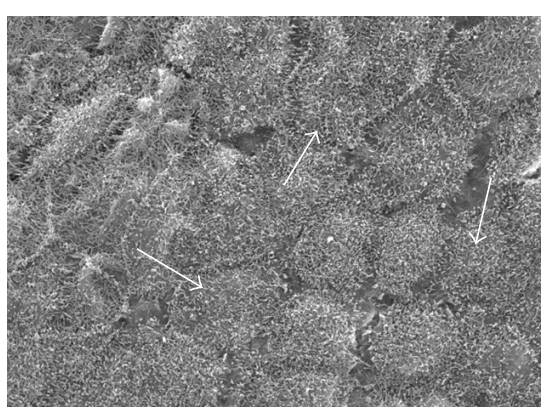

(b)

FIGURE 5: Mesothelial surface from rats $12 \mathrm{~h}$ after insufflation with heated humidified $\mathrm{CO}_{2}$ for $2 \mathrm{~h}$ at $5 \mathrm{~mm} / \mathrm{Hg}$ (group 4). The cells are tightly apposed with cytoplasmic projections (microvilli) prominent (arrows). While some rounding of the cells is evident (open arrow), overall this group showed the least effects from the induced environment: (a) original $\times 650$; (b) original $\times 3500$.

likely to cause exaggerated damage due to the high pressures, flow rates, and long durations of pneumoperitoneum $[4,6,10,33]$. Furthermore, direct comparisons between heated/humidified, heated/dry, and cold/dry $\mathrm{CO}_{2}$ are needed to elucidate the effects of the different combinations on the peritoneum.

Within the current study, our aim was to use conservative conditions to compare the effects of the three different temperature/humidity combinations on mesothelial cells. The $2 \mathrm{~h}$ pneumoperitoneum was chosen as a moderate time with the pressure within the criteria recommended by Avital et al. [10]. In addition, the use of a heating blanket to maintain normothermia reduced the potential impact of hypothermia as a confounding variable in our study. Previously it has been demonstrated that mesothelial changes of the type we were investigating are most apparent at $12 \mathrm{~h}$ after surgery [7], and so this was used to compare whether heating and/or humidification had any protective effects.

Our results strongly suggest that under the conditions of the study, cold/dry $\mathrm{CO}_{2}$ caused mesothelial damage comparable to that previously reported [7], with little protection provided by heating the gas. In contrast, heating with humidification protected the mesothelial cells such that there was little deviation from the control animals. This is supported by the findings of other studies albeit under more extreme experimental conditions $[4,6]$. In contrast, Hazebroek et al. found no difference between warm/dry, cold/dry, and warm/humidified $\mathrm{CO}_{2}$ [34]. There are a number of potential reasons for this. Hazebroek et al. used a $2 \mathrm{~h}$ and a $24 \mathrm{~h}$ time point to sacrifice the animals and obtain the tissues rather than the $12 \mathrm{~h}$ time point used in our study. In addition, the different methods of anaesthesia may have impacted the findings. We used inhaled isoflurane to avoid any direct irritation within the peritoneum from the anaesthetic whereas Hazebroek et al. used intraperitoneal pentobarbitone administered every $30 \mathrm{~min}$. Pentobarbitone is known to have irritant effects [35] which may have significantly contributed to the mesothelial damage. This hypothesis is supported by the fact that the group with mechanical abdominal wall lifting in the study showed similar damage to the three insufflation groups, indicating that pneumoperitoneum was not the cause of the mesothelial damage.
The results from this study demonstrate that heated and humidified $\mathrm{CO}_{2}$ provides much greater protection of the mesothelium compared to either heated or cold dry gas in rats at insufflation pressures and times comparable with human surgery.

\section{Conflict of Interests}

Jessica Hayward and Jean K. Marshall are employees of Fisher and Paykel Healthcare. The senior authors on the study, Professor Andrew K. Davey and Associate Professor Anthony E. Woods, are both independent academics with no conflict of interests.

\section{Acknowledgments}

The authors wish to thank Nicole Sanders and Andrew Beck for technical support during this project. This work was funded by Fisher and Paykel Healthcare.

\section{References}

[1] S. J. Neuhaus, A. Gupta, and D. I. Watson, "Helium and other alternative insufflation gases for laparoscopy: a review," Surgical Endoscopy, vol. 15, no. 6, pp. 553-560, 2001.

[2] S. S. Davis, D. J. Mikami, M. Newlin et al., "Heating and humidifying of carbon dioxide during pneumoperitoneum is not indicated: a prospective randomized trial," Surgical Endoscopy and Other Interventional Techniques, vol. 20, no. 1, pp. 153-158, 2006.

[3] United States Pharmacopoeia and the National Formulary Supplements, 26-NF 21, United States Pharmacopeial Convention, Easton, NJ, USA, 3rd edition, 2003.

[4] M. Erikoglu, S. Yol, M. C. Avunduk, E. Erdemli, and A. Can, "Electron-microscopic alterations of the peritoneum after both cold and heated carbon dioxide pneumoperitoneum," Journal of Surgical Research, vol. 125, no. 1, pp. 73-77, 2005.

[5] S. J. Neuhaus and D. I. Watson, "Pneumoperitoneum and peritoneal surface changes-a review," Surgical Endoscopy and Other Interventional Techniques, vol. 18, no. 9, pp. 1316-1322, 2004.

[6] Y. Peng, M. Zheng, Q. Ye, X. Chen, B. Yu, and B. Liu, "Heated and humidified $\mathrm{CO}_{2}$ prevents hypothermia, peritoneal injury, 
and intra-abdominal adhesions during prolonged laparoscopic insufflations," Journal of Surgical Research, vol. 151, no. 1, pp. 4047, 2009.

[7] J. Volz, S. Köster, Z. Spacek, and N. Paweletz, "Characteristic alterations of the peritoneum after carbon dioxide pneumoperitoneum," Surgical Endoscopy, vol. 13, no. 6, pp. 611-614, 1999.

[8] S. Köster, Z. Spacek, N. Paweletz, and J. Volz, "The effect of a $\mathrm{CO}_{2}$-pneumoperitoneum of the peritoneal surface in mice. A scanning electron microscopy study," Zentralblatt fur Gynakologie, vol. 121, no. 5, pp. 244-247, 1999.

[9] M. I. Puttick, D. M. Scott-Coombes, J. Dye et al., "Comparison of immunologic and physiologic effects of $\mathrm{CO}_{2}$ pneumoperitoneum at room and body temperatures," Surgical Endoscopy, vol. 13, no. 6, pp. 572-575, 1999.

[10] S. Avital, R. Itah, S. Szomstein et al., "Correlation of $\mathrm{CO}_{2}$ pneumoperitoneal pressures between rodents and humans," Surgical Endoscopy and Other Interventional Techniques, vol. 23, no. 1, pp. 50-54, 2009.

[11] S. Matsuzaki, K. Jardon, E. Maleysson et al., "Carbon dioxide pneumoperitoneum, intraperitoneal pressure, and peritoneal tissue hypoxia: a mouse study with controlled respiratory support," Surgical Endoscopy and Other Interventional Techniques, vol. 24, no. 11, pp. 2871-2880, 2010.

[12] T. Sammour, A. Kahokehr, and A. G. Hill, "Independent testing of the Fisher \& Paykel Healthcare MR860 Laparoscopic Humidification System," Minimally Invasive Therapy and Allied Technologies, vol. 19, no. 4, pp. 219-223, 2010.

[13] T. Sammour, A. Mittal, B. Delahunt, A. R. J. Phillips, and A. G. Hill, "Warming and humidification have no effect on oxidative stress during pneumoperitoneum in rats," Minimally Invasive Therapy and Allied Technologies, vol. 20, no. 6, pp. 329-337, 2011.

[14] K. Michailova, W. Wassilev, and T. Wedel, "Scanning and transmission electron microscopic study of visceral and parietal peritoneal regions in the rat," Annals of Anatomy, vol. 181, no. 3, pp. 253-260, 1999.

[15] J. H. Crabtree, "Heated, humidified $\mathrm{CO}_{2}$ gas is unsatisfactory for awake laparoscopy," Journal of the Society of Laparoendoscopic Surgeons, vol. 9, no. 4, pp. 463-465, 2005.

[16] S. A. Jackson, A. S. Laurence, and J. C. Hill, "Does postlaparoscopy pain relate to residual carbon dioxide?" Anaesthesia, vol. 51, no. 5, pp. 485-487, 1996.

[17] M. M. Binda, C. R. Molinas, K. Mailova, and P. R. Koninckx, "Effect of temperature upon adhesion formation in a laparoscopic mouse model," Human Reproduction, vol. 19, no. 11, pp. 2626-2632, 2004.

[18] M. Canis, R. Botchorishvili, A. Wattiez et al., "Cancer and laparoscopy, experimental studies: a review," European Journal of Obstetrics Gynecology and Reproductive Biology, vol. 91, no. 1, pp. 1-9, 2000.

[19] Y. T. Wong, P. C. Shah, D. H. Birkett, and D. M. Brams, "Carbon dioxide pneumoperitoneum causes severe peritoneal acidosis, unaltered by heating, humidification, or bicarbonate in a porcine model," Surgical Endoscopy and Other Interventional Techniques, vol. 18, no. 10, pp. 1498-1503, 2004.

[20] S. Yilmaz, C. Polat, A. Kahraman et al., "The comparison of the oxidative stress effects of different gases and intraabdominal pressures in an experimental rat model," Journal of Laparoendoscopic and Advanced Surgical Techniques Part A, vol. 14, no. 3, pp. 165-168, 2004.

[21] J. R. Bessell, G. Ludbrook, S. H. Millard, P. S. Baxter, S. S. Ubhi, and G. J. Maddern, "Humidified gas prevents hypothermia induced by laparoscopic insufflation: a randomized controlled study in a pig model," Surgical Endoscopy, vol. 13, no. 2, pp. 101105, 1999.

[22] R. Corona, J. Verguts, R. Koninckx, K. Mailova, M. M. Binda, and P. R. Koninckx, "Intraperitoneal temperature and desiccation: during endoscopic surgery Intraoperative humidification and cooling of the peritoneal cavity can reduce adhesions," American Journal of Obstetrics and Gynecology, vol. 205, no. 4, pp. e1-e7, 2011.

[23] Y. Yu, J. Kuebler, S. Groos et al., "Carbon dioxide modifies the morphology and function of mesothelial cells and facilitates transepithelial neuroblastoma cell migration," Pediatric Surgery International, vol. 26, no. 1, pp. 29-36, 2010.

[24] G. S. DiZerega and J. D. Campeau, "Peritoneal repair and postsurgical adhesion formation," Human Reproduction Update, vol. 7, no. 6, pp. 547-555, 2001.

[25] T. Suematsu, Y. Hirabayashi, N. Shiraishi, Y. Adachi, H. Kitamura, and S. Kitano, "Morphology of the murine peritoneum after pneumoperitoneum vs laparotomy: a scanning electron microscopy study," Surgical Endoscopy, vol. 15, no. 9, pp. 954958, 2001.

[26] J. Du, P.-W. Yu, and B. Tang, "Application of stereology to study the effects of pneumoperitoneum on peritoneum," Surgical Endoscopy and Other Interventional Techniques, vol. 25, no. 2, pp. 619-627, 2011.

[27] M. M. Binda, C. R. Molinas, P. Hansen, and P. R. Koninckx, "Ef$\%$ fect of desiccation and temperature during laparoscopy on adhesion formation in mice," Fertility and Sterility, vol. 86, no. 1, pp. 166-175, 2006.

[28] V. L. Wills, D. R. Hunt, and A. Armstrong, "A randomized controlled trial assessing the effect of heated carbon dioxide for insufflation on pain and recovery after laparoscopic fundoplication," Surgical Endoscopy, vol. 15, no. 2, pp. 166-170, 2001.

[29] R. Benavides, A. Wong, and H. Nguyen, "Improved outcomes for lap-banding using the insuflow® device compared with heated-only gas," Journal of the Society of Laparoendoscopic Surgeons, vol. 13, no. 3, pp. 302-305, 2009.

[30] T. M. Beste, J. A. Daucher, and D. Holbert, "Humidified compared with dry, heated carbon dioxide at laparoscopy to reduce pain," Obstetrics and Gynecology, vol. 107, no. 2, pp. 263-268, 2006.

[31] D. E. Ott, H. Reich, B. Love et al., "Reduction of laparoscopicinduced hypothermia, postoperative pain and recovery room length of stay by pre-conditioning gas with the Insuflow device: a prospective randomized controlled multi-center study," Journal of the Society of Laparoendoscopic Surgeons, vol. 2, no. 4, pp. 321-329, 1998.

[32] P. A. Glew, M. J. J. Campher, K. Pearson, J. C. Schofield, and A. K. Davey, "The effect of warm humidified $\mathrm{CO}_{2}$ on the dissipation of residual gas following laparoscopy in piglets," Journal of the American Association of Gynecologic Laparoscopists, vol. 11, no. 2, pp. 204-210, 2004.

[33] M. Gagner, "High-pressure carbon dioxide pneumoperitoneum before major liver resection in a rat model is not realistic and cannot be transposed to humans when studying liver regeneration," Surgical Endoscopy and Other Interventional Techniques, vol. 25, no. 3, pp. 988-989, 2011.

[34] E. J. Hazebroek, M. A. Schreve, P. Visser, R. W. F. De Bruin, R. L. Marquet, and H. J. Bonjer, "Impact of temperature and humidity of carbon dioxide pneumoperitoneum on body temperature and peritoneal morphology," Journal of Laparoendoscopic and 
Advanced Surgical Techniques Part A, vol. 12, no. 5, pp. 355-364, 2002.

[35] O. Svendsen, L. Kok, and B. Lauritzen, "Nociception after intraperitoneal injection of a sodium pentobarbitone formulation with and without lidocaine in rats quantified by expression of neuronal c-fos in the spinal cord-a preliminary study," Laboratory Animals, vol. 41, no. 2, pp. 197-203, 2007. 


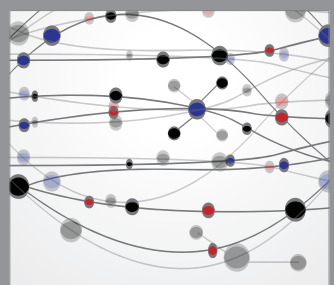

The Scientific World Journal
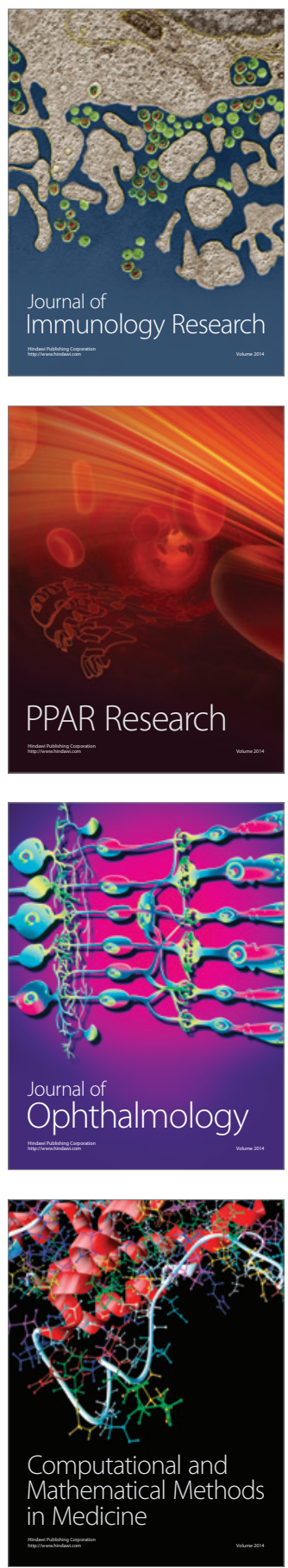

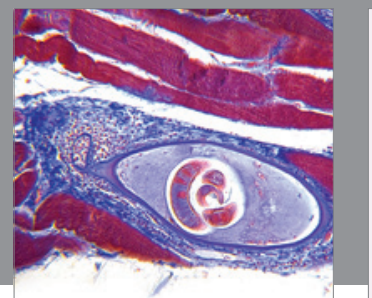

Gastroenterology

Research and Practice
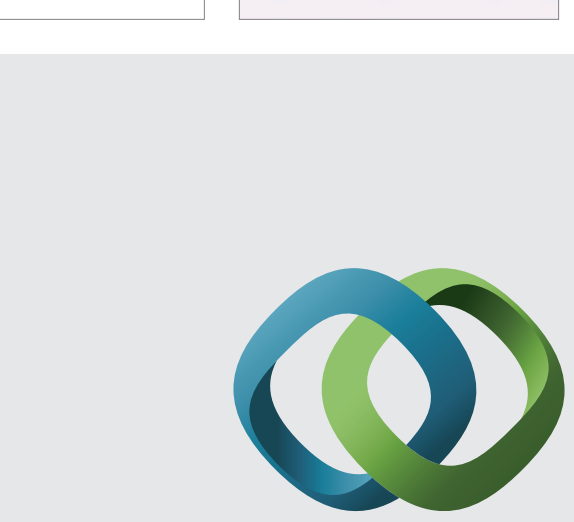

\section{Hindawi}

Submit your manuscripts at

http://www.hindawi.com
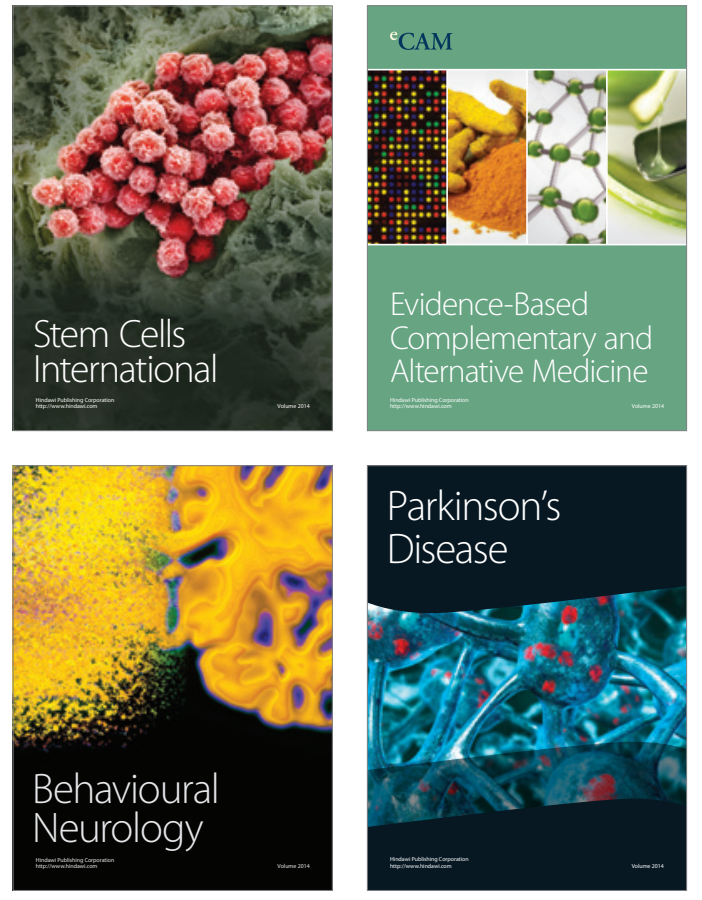
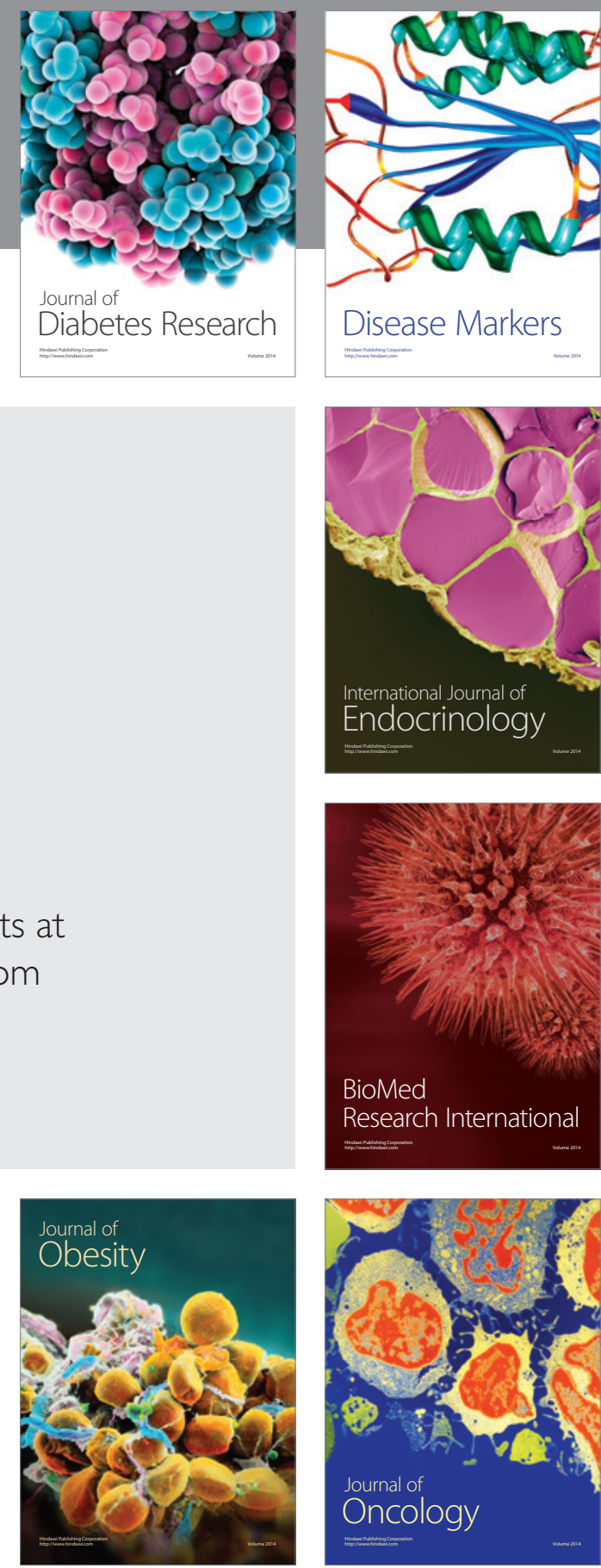

Disease Markers
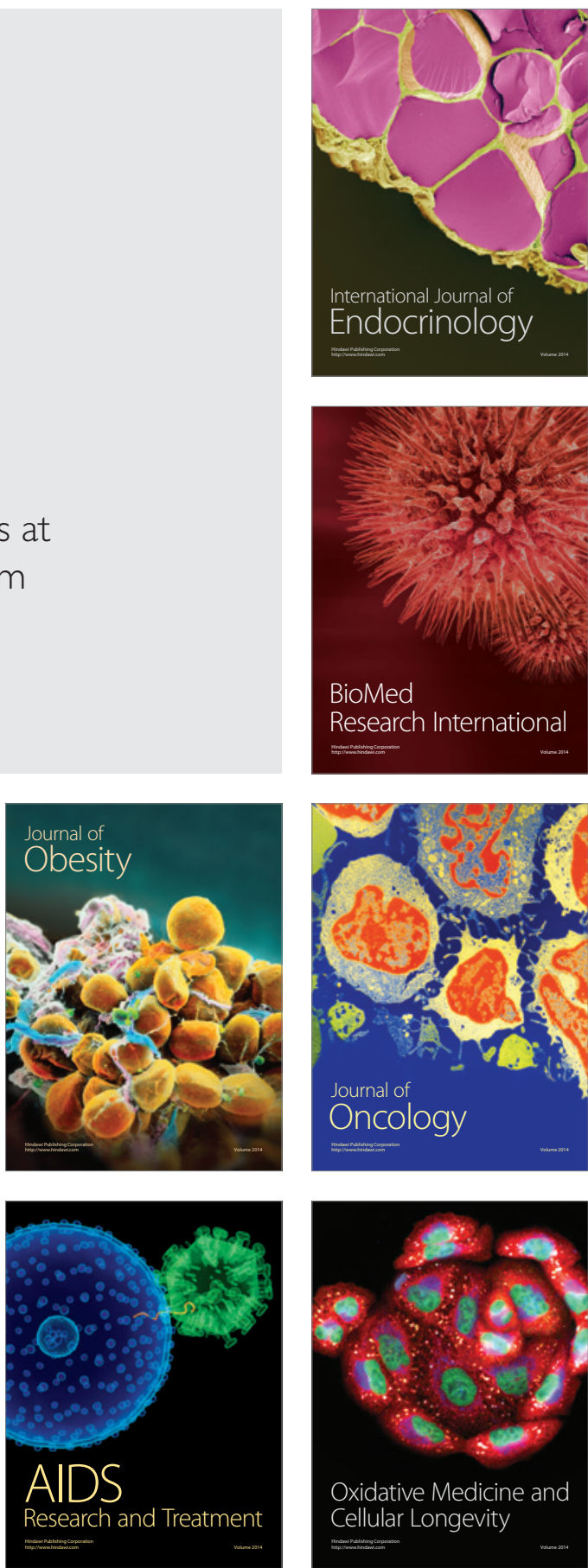